regards production and consumption; nutritional needs and national fitness; population problems and genetics questions; scientific agriculture, afforestation, land reclamation; regional distribution of industry; hydro-electric power, new industrial developments (light metals, carbide and acetylene, plastics, cellulose, synthetic fats); aircraft and poison gas defence; psychology and war; educational use of cinema; vocational outlet for trained workers; and several others. These are to be grouped around the various sciences to which they are related. The chairman (Sir Richard Gregory) referring to the fact that many of these problems have been discussed at recent meetings of the British Association, suggested that the closest co-operation be maintained with the Association, and it was agreed that, if possible, suggestions be made to recorders of suitable sections for the inclusion of such papers in the programme of the next meeting at Nottingham. Material on the above or other suitable topics should be sent to the Honorary Secretary, Research Co-ordination Committee, Hazlitt House, Southampton Buildings, W.C.2 (Telephone, Holborn 1713).

\section{Relativity and the Quantum Theory}

IN a lecture given before the Newcastle-upon-Tyne Astronomical Society on Novernber 5, Prof. R. A. Sampson discussed "The Spectroscope in the Observatory". Remarking that the spectrum, along with Wilson's cloud chamber and photographs of diffraction patterns due to electrons, furnishes visible records of things that are too small to see, Prof. Sampson pointed out that Dirac holds it is quite impossible to make a rational theory of these things without reconstructing our ideas of the nature of matter altogether. This has led to the two great theories of modern times, namely, relativity and the quantum theory. They are not yet fully reconciled. In his opinion, there are considerable philosophical diffeulties in holding either. Relativity, on its merits, may seem a probable theory, but it cannot do its feats without making time an equal co-ordinate with the familiar three of space. Now we cannot think time away, without sacrificing the possibility of expressing ourselves intelligibly to others, and living in a world where history and cause and effect have no meaning. Nor does it upset our own affairs alone; we see the grass grow in summer and die away in winter. That must be an illusion. It seems to Prof. Sampson a simpler hypothesis to suppose that the intellect is limited. The quantum theory, which is obviously on the right lines, makes in small matters an enormous logical difference, and gives a new meaning to the question "Will the sun rise tomorrow ?"-for example, when we are dead, or last century, before we were born. We must confess that we have no means of verifying whether it does or not. It seems that both these theories spell the exhaustion of the constructs of the intellect, of which a necessary part is the four elements of space-time, which must be exhausted sooner or later. Leaving these philosophical questions, Prof. Sampson gave a description of the ordinary theory of stellar sequences, etc., including the Russell diagram of the relation of luminosity to spectral class, and white dwarfs.

\section{Supervision of the Nation's Food Supply}

IN the fifteenth Benjamin Ward Richardson Lecture which was delivered on November 10 before the Royal Sanitary Institute, Dr. Gerald Leighton, late Medical Officer of the Department of Health for Scotland, stated that from the public health point of view three conditions are required for the proper supervision of the nation's food supply. In the first place, there must be a concentration and collection at certain centres of large quantities of the food material, so that there may be adequate inspection. Although the necessity of this condition was recognized more than forty years ago by the United States Department of Agriculture, which established a wellregulated system of slaughter houses, Great Britain has been very slow in adopting the system of public abattoirs, the need of which was so strongly urged by Benjamin Ward Richardson himself. The second condition necessary for effective supervision is the supply of a sufficient number of highly trained inspectors. Great progress has been made in this respect during the last twenty years, training for students as meat inspectors being provided by veterinary colleges, some universities and other educational bodies. Lastly, a uniformity of system and practice is essential. The inspectors should be trained to work on a uniform system and to a uniform standard instead of, as in the old days, each inspector being a law to himself. Dr. Leighton then dwelt on the desirability of securing and adopting the most rapid, skilled and humane methods of slaughtering all kinds of animals for human food, a topic which formed part of the life work of Richardson. In conclusion, he expressed the view that in the progress of the supervision of a nation's food, the introduction. of legal standards, as in most European countries, America and various parts of the Empire, for the majority of foods is the most important step for future development.

\section{The London Telephone Trunk Exchange}

Is a paper read on November 13 to the Students' Section of the Institution of Electrical Engineers, Mr. H. M. Wells discusses the effects of the rapid increase of the telephone service in Great Britain on the methods of working. The country is divided up into zone areas and subdivided into group areas. Major trunk lines connect main zone exchanges with London and with one another. They are so designed that a minimum of duplicate plant is necessary. By the use of thermionic amplifiers, the volume of speech fed into a line is made equal to the volume received at the far end. When things are properly adjusted, there is thus no loss of sound. One result is that the speech on the London-Moscow circuit is as good as that on a local London call. The insula. tion materials of the cables used are paper and 'air-space'. The 'air-space' is filled with carbon dioxide which possesses desiccating qualities and 